\title{
The Informational Content of Initial Public Offerings
}

\author{
IAN GALE and JOSEPH E. STIGLITZ*
}

\begin{abstract}
The ability of capital markets to distinguish firms of different value by the size of their initial equity offerings is attenuated when insiders can sell equity more than once. A model is developed in which there is price risk from holding equity between periods. When the uncertainty is small, there must be pooling in the first period. When uncertainty is large, the pooling equilibria dominate the separating equilibrium.
\end{abstract}

THE SIZE OF AN entrepreneur's initial public offering of equity can be informative. This point was made in Leland and Pyle (1977) and Stiglitz (1982). An entrepreneur with a good project can signal the value of the project by his or her willingness to retain equity. An implicit assumption of this analysis is that the entrepreneur has only one opportunity to sell equity.

The assumption of a single sale is important since, once the entrepreneur has signalled his or her project value by retaining equity, investors should be willing to purchase the remaining equity. However, if entrepreneurs with bad projects foresee this, they too may wish to retain equity initially and render themselves indistinguishable from entrepreneurs with good projects.

The current paper develops a model with two trading periods to capture the impact of having repeat sales of equity. There is a public offering in the first period. Then the entrepreneur can make an open-market sale in the second period. However, there is exogenous price risk, which makes it costly for the entrepreneur to wait to sell. In this context the value of the entrepreneur's project may not be revealed in the first period.

Retaining equity is not very costly when uncertainty is small, and there will only be pooling equilibria in this case. In such a situation, no information is revealed in the first period. When the level of uncertainty is great, there does exist a separating equilibrium. However, the pooling equilibria Pareto-dominate the separating equilibrium. Throughout the analysis the focus will be on Paretooptimal equilibria.

The idea that an informed agent can profitably trade over time has been examined in related contexts. Kyle (1985) looked at the optimal trading strategy for an insider whose sequence of purchases is hidden in the aggregate order flow. In equilibrium, the insider's information is not completely incorporated into the market price until the close of trading.

\footnotetext{
* Department of Economics, University of Wisconsin and Department of Economics, Stanford University, respectively. We are grateful to Don Hester, Nobu Kiyotaki, René Stulz (the editor), and an anonymous referee for helpful suggestions and comments.
} 
Gale (1987) studies an informed hedger trading with competitive market makers. Since a hedger can make several purchases, he or she does not reveal his or her information with the first trade, even though the terms are public knowledge. The hedging motive leads some hedgers to purchase at prices above their estimate of expected value and thus keeps the market from breaking down.

After the current paper was completed, we became aware of two papers that focus on the underpricing of initial public offerings. The idea of using underpricing as a signal is that the willingness to "burn money" can be an indication that one's firm is good.

In Welch (1989), firms must incur an operating cost which is value enhancing for a good firm but simply an imitation cost for a bad firm. Three equilibria are studied. In one equilibrium there is underpricing of equity by the good firm. If the probability of detection is low, however, there is also an equilibrium in which the two types pool and sell the same quantity in the first period.

Grinblatt and Hwang (1988) study the problem of firms trying to signal expected return and variance simultaneously. Two signals are needed to communicate these two pieces of information. The degree of underpricing, in conjunction with the amount of equity retained, signals project value.

In both of these papers there is positive probability that a low-value firm would be detected after having imitated the high-value firm. The possibility that one's attempt at imitation might be for naught may deter low-value firms from imitating high-value firms. In the present paper, the costs borne in mimicking can be undone in the second period.

This paper is organized as follows: Section I describes the model. Section II analyzes the equilibria. The summary is in Section III.

\section{The Model}

A single entrepreneur has a project that he or she will choose whether to undertake. The project has a total return given by

$$
\tilde{V}=\tilde{s}+\tilde{z}_{1}+\tilde{z}_{2} \text {. }
$$

The return is independent of the market (i.e., $\beta=0$ ). The project takes on one of two possible values: $s_{H}$ or $s_{L}$. If $\tilde{s}=s_{H}$, we refer to the entrepreneur as a "high type" or a "type $H$. ." For $\tilde{s}=s_{L}$, the entrepreneur is a "low type" or a "type $L$." The entrepreneur alone knows the value of $\tilde{s}$.

The noise terms $\tilde{z}_{1}$ and $\tilde{z}_{2}$ have zero means and are independent of $\tilde{s}$. These shocks are idiosyncratic demand-side disturbances. We also assume that $\tilde{V} \geq 0$, so limited liability will not be a concern.

The entrepreneur sees $\tilde{s}$ at $t=0$ and then decides whether to undertake the project. The entrepreneur initially pays the capital cost $K$ out of personal wealth $W_{0}$ and then seeks equity financing to reduce the exposure to risk. (If $W_{0}<K$, or if there is a minimum amount of revenue that must be raised in the first period, there will be a floor on the initial sale. This alone could force the type $H$ to pool in the first period.)

The net present values of the two project types are assumed to be positive:

$$
s_{H}>s_{L}>K \text {. }
$$


The interest rate is assumed to be zero. Thus, both types of projects would be undertaken in equilibrium since the entrepreneur could always tender all equity in the first trading period for a price no lower than $s_{L}$ and get a net return of $s_{L}$ $-K>0$.

At $t=1$ the entrepreneur has the opportunity to issue equity to risk-neutral investors. After the sale the demand shock $\tilde{z}_{1}$ is seen publicly. At $t=2$ the entrepreneur has an opportunity to sell more equity from personal holdings. Then the signal $\tilde{z}_{2}$ is seen and the value of the asset is revealed publicly at $t=3$.

The entire return of the project is realized in period 3 . The entrepreneur's random gross return is

$$
\tilde{R}=p_{1} q_{1}+p_{2} q_{2}-\tilde{V}\left(1-q_{1}-q_{2}\right),
$$

where $q_{j}$ is the quantity that the entrepreneur offers for sale in period $j, p_{j}$ is the price paid, and $1-q_{1}-q_{2}$ is the amount of equity still held by the entrepreneur entering period 3 . Terminal wealth can therefore be written $\tilde{W}=W_{0}-K+\tilde{R}$.

The entrepreneur is risk averse and maximizes the expected utility of terminal wealth. It is assumed that the utility function exhibits decreasing absolute risk aversion. Expected utility is written as a function of the gross return: $E U(\tilde{R}) \equiv$ $E U\left(\tilde{W}-W_{0}+K\right)$.

If the entrepreneur is endowed with a high-value project, the equilibrium sales are denoted $H_{1}$ and $H_{2}$. The low type's sales are $L_{1}$ and $L_{2}$. In each of the two periods the entrepreneur announces the quantity for sale, and investors then respond simultaneously with their offered prices. The equity will be divided evenly among all investors who offer the highest price whenever there is a tie.

The prices that investors offer are conditioned on their prior beliefs as to the project's value and on the information that can be gleaned from the sizes of the offerings of equity made by the entrepreneur. The initial beliefs are that $\tilde{s}=s_{H}$ with probability $\omega_{H}$ and $\tilde{s}=s_{L}$ with probability $\omega_{L}$. These prior beliefs are denoted $\pi_{0}=\left(\omega_{H}, \omega_{L}\right)$.

After a trade has taken place at $t=1$, market makers revise their beliefs. These new beliefs are written $\pi\left(q_{1}\right)$. After a trade has taken place at $t=2$, the beliefs are written $\pi\left(q_{1}, q_{2}\right)$. Once the investors are certain of the entrepreneur's type, they do not subsequently revise their beliefs. Thus, if $\pi\left(q_{1}\right)=(1,0)$, for example, then $\pi\left(q_{1}, q_{2}\right)=(1,0)$ also.

Signalling models explicitly or implicitly use a Bayesian-Nash equilibrium solution concept. This requires first that beliefs about players' types be consistent. In the present context the consistency requirement means that investors' beliefs as to the entrepreneur's type must be updated using Bayes' rule applied to the equilibrium strategies. For dynamic games one must also ensure that, for any possible history of actions, the strategies are mutual best responses.

The equilibrium concept that will be used here is the sequential equilibrium of Kreps and Wilson (1982). An equilibrium is characterized by strategies from investors and the entrepreneur, and beliefs as to the entrepreneur's type, such that the following conditions hold:

1. Each player's strategy is sequentially rational: starting from any possible history of sales, the strategy maximizes that player's expected payoff, given investors' beliefs and the strategies of all other players. 
2. The investors' beliefs as to the entrepreneur's type are consistent with Bayes' rule applied to the strategy of the entrepreneur along the equilibrium path.

The next section looks at the case where both project types have a positive net present value. When the amount of uncertainty is small, there must be pooling at $t=1$ in equilibrium. When there is a large amount of uncertainty, there can be both pooling and separation at $t=1$. However, even when a separating equilibrium exists, the high type strictly prefers to pool.

\section{Equilibrium When Both Project Types Have a Positive Value}

Some general results will be presented first. The pooling price $\bar{p}$ is defined as the expected value of the project before the first offering of equity is made. That is, $\bar{p} \equiv \omega_{H} s_{H}+\omega_{L} s_{L}$. It can now be shown that an entrepreneur always receives a price equal to the expected value of the project conditional on all publicly available information.

LEMMA 1: If there is pooling at $t=1$, then the price paid is $\bar{p}$. At $t=2$, the price is $\bar{p}+z_{1}$. If the two types sell different quantities at $t=1$, the type $j$ will receive a price $s_{j} ; j=L, H$. At $t=2$, the type $j$ will receive $s_{j}+z_{1}$ if the two types sell different quantities.

Proof: Suppose first that $L_{1}=H_{1}$. It is clear that, if a price above $\bar{p}$ is offered, then some investor is taking an expected loss. If the best price offered by investors is below $\bar{p}$, some investor will offer a marginally higher price and get all of the equity. Thus, if the two types sell the same quantity in period 1 , they must receive the price $\bar{p}$. Similarly, if $L_{2}=H_{2}$ the price is $\bar{p}+z_{1}$.

Now suppose that the two types sell different quantities at $t=1$. The best price offered to the type $j$ must equal $s_{j}$ or else some investor will offer a higher price and get all of the equity. Similarly, at $t=2$ the best price offered to a type $j$ must equal $s_{j}+z_{1}$ or an investor can profitably offer a higher price and get all of the equity. Q.E.D.

There cannot be pooling in both periods of a Pareto-optimal equilibrium. If there were pooling in both periods, both types would be strictly better off selling $q_{1}+q_{2}$ in the first period instead. If both types sell an amount $q_{1}$ in the first period, the largest quantity that the type $H$ could sell in period 2 without being mimicked will be denoted $Q\left(q_{1}\right)$. (This is also a function of the realization of $\tilde{z}_{1}$, but we will suppress that argument.) The next lemma demonstrates that there is a separating equilibrium in the second period in which the type $H$ does sell $Q\left(q_{1}\right)$.

LEMMA 2: If both types sell a quantity $q_{1}$ at $t=1$, there is an equilibrium in the second period in which the type $L$ sells $1-q_{1}$, while the type $H$ sells $Q\left(q_{1}\right), 0<$ $Q\left(q_{1}\right)<1-q_{1}$.

Proof: The first step is to show that for a given $q_{1}$ there is a maximum value of $q_{2}$ such that the type $L$ would not mimic if the type $H$ sold $q_{2}$ in the second period. If the type $L$ separates at $t=2$, the price that is paid is $s_{L}+z_{1}$. Since the entrepreneur is risk averse, the type $L$ will sell the entire quantity $1-q_{1}$ upon 
separation. If the type $L$ were to deviate and mimic the type $H$ at $t=2$, he or she would receive the price $s_{H}+z_{1}$ for the quantity $q_{2}$ and would be left holding a quantity $1-q_{1}-q_{2}$. The type $L$ is just indifferent to mimicking at $t=2$ if

$$
\begin{aligned}
& U\left(\bar{p} q_{1}+\left(s_{L}+z_{1}\right)\right.\left.\left(1-q_{1}\right)\right) \\
&=E U\left(\bar{p} q_{1}+\left(s_{H}+z_{1}\right) q_{2}+\left(s_{L}+z_{1}+\tilde{z}_{2}\right)\left(1-q_{1}-q_{2}\right)\right) .
\end{aligned}
$$

Define $F(q) \equiv E U\left(\bar{p} q_{1}+\left(s_{H}+z_{1}\right) q+\left(s_{L}+z_{1}+\tilde{z}_{2}\right)\left(1-q_{1}-q\right)\right) . F(\cdot)$ is a continuous and strictly increasing function for $0<q<1-q_{1}$. Moreover, $F(0)$ is strictly less than the left-hand side of (4), whereas $F\left(1-q_{1}\right)$ is strictly greater. Thus, there is a unique value of $q_{2}$ that solves (4), and we write $Q(\cdot)$ as the function that solves (4) for every quantity of first-period sales.

The final step in the proof is to show that there can be separation at $t=2$ in an equilibrium. Let the beliefs be $\pi\left(q_{1}, q_{2}\right)=(1,0)$ if $q_{2} \leq Q\left(q_{1}\right)$, and let $\pi\left(q_{1}, q_{2}\right)$ $=(0,1)$ for $q_{2}>Q\left(q_{1}\right)$. Lemma 1 shows that the best price offered to a type $j$ must equal $s_{j}+z_{1}$. It is optimal for the type $H$ to sell exactly $Q\left(q_{1}\right)$ and for the type $L$ to sell $1-q_{1}$. Q.E.D.

The previous two lemmas are independent of the amount of uncertainty that is resolved before $t=2$. The outcome that occurs in the first trading period will depend on the cost of waiting to sell, which in turn depends directly on the amount of demand-side uncertainty. The following condition is satisfied when there is a large amount of uncertainty present:

$$
U\left(s_{L}\right)>E U\left(s_{H}+\tilde{z}_{1}\right) .
$$

The size of the offerings that the type $H$ makes when there is separation at $t=$ 1 can now be characterized.

Lemma 3: Suppose that (5) is satisfied. The type $H$ sells $H_{1}=q^{s}$ and $H_{2}=1-q^{s}$ in a separating equilibrium, where $q^{s}$ is the unique solution to $U\left(s_{L}\right)=E U\left(s_{H}+\right.$ $\left.\tilde{z}_{1}\left(1-q^{s}\right)\right)$.

Proof: If the two types sell different quantities at $t=1$, the type $L$ will be offered the price $p_{1}=s_{L}$. The optimal sale in this case is $L_{1}=1$ since the entrepreneur is risk averse. If the type $L$ were to imitate, he or she would sell $H_{1}$ at the price $s_{H}$ and then would sell $1-H_{1}$ at $t=2$ for the price $s_{H}+z_{1}$. The type $L$ will not have an incentive to mimic if

$$
U\left(s_{L}\right) \geq E U\left(s_{H}+\tilde{z}_{1}\left(1-H_{1}\right)\right) .
$$

The right-hand side of (6) is a continuous and increasing function of $H_{1}$ for $H_{1}$ $\leq 1$. When $H_{1}=0$, the right-hand side is smaller, by (5). When $H_{1}=1$, the righthand side is larger. Thus, the type $H$ can separate at $t=1$ by selling $H_{1} \leq q^{s}$. However, if $H_{1}<q^{s}$, the type $H$ would be better off mimicking the type $L$ and selling $H_{1}=1$ for a price $s_{L}$. Hence, $q^{s}$ is the unique quantity that the type $H$ sells in period 1 in a separating equilibrium, and $1-q^{s}$ is sold at $t=2$. Q.E.D.

The optimal quantity for the type $H$ to sell in the first period of a (purestrategy) pooling equilibrium is defined by

$$
q^{P} \equiv \operatorname{argmax}_{q} E U\left(\bar{p} q+\left(s_{H}+\tilde{z}_{1}\right) Q(q)+\left(s_{H}+\tilde{z}_{1}+\tilde{z}_{2}\right)(1-q-Q(q))\right) .
$$


The last lemma in this section demonstrates that both types strictly prefer to pool and sell $q^{P}$ at $t=1$ when the expected project value is high. Note that a high expected value corresponds to a large prior probability that the project has a high value.

LEMMA 4: There is a minimum price $\hat{p}, s_{L}<\hat{p}<s_{H}$, such that both types strictly prefer to pool and sell $q^{P}$ at $t=1$, rather than separate, when $\bar{p}>\hat{p}$.

Proof: Pooling is strictly preferred by the type $L$ if

$$
E U\left(\bar{p} q^{p}+\left(s_{L}+\tilde{z}_{1}\right)\left(1-q^{p}\right)\right)>U\left(s_{L}\right) .
$$

Suppose that $\bar{p}=s_{H}$. In this case $q^{P}=1$. Since $q^{P}$ is a continuous function of $\bar{p}$, the left-hand side of (8) is also a continuous function of $\bar{p}$. Thus, there is an interval of the form $\left(\hat{p}, s_{H}\right]$ such that $(8)$ is satisfied for $\bar{p}>\hat{p}$. In particular, there is a minimum price $\hat{p}<s_{H}$ such that (8) is satisfied when the pooling price $\bar{p}>$ $\hat{p}$. This condition on $\bar{p}$ means that the project is very likely to have a high value. That is, $\omega_{H}>\left(\hat{p}-s_{L}\right) /\left(s_{H}-s_{L}\right)$.

It is also clear that $\hat{p}$ exceeds $s_{L}$. If $\dot{p}=s_{L}+\varepsilon$, then $q^{P}<1$. It follows that $E U\left(\bar{p} q^{P}+\left(s_{L}+\tilde{z}_{1}\right)\left(1-q^{P}\right)\right)<E U\left(s_{L}+\varepsilon+\tilde{z}_{1}\left(1-q^{P}\right)\right)<U\left(s_{L}\right)$, for small $\varepsilon$. Hence, the type $L$ would optimally choose to separate and sell $L_{1}=1$ if $\bar{p}=$ $s_{L}+\varepsilon$.

If the type $L$ prefers to pool when $\bar{p}>\hat{p}$, then so must the type $H$. Pooling at $t=1$ gives the type $H$ expected utility:

$$
\begin{aligned}
E U\left(\bar{p} q^{P}+\left(s_{H}+\tilde{z}_{1}\right) Q\left(q^{P}\right)+\left(s_{H}+\tilde{z}_{1}+\tilde{z}_{2}\right)\left(1-q^{P}-Q\left(q^{P}\right)\right)\right) & \\
& >E U\left(\bar{p} q^{P}+\left(s_{L}+\tilde{z}_{1}\right)\left(1-q^{P}\right)\right)>U\left(s_{L}\right),
\end{aligned}
$$

by (4) and (8). However the type $H$ receives expected utility of $U\left(s_{L}\right)$ in a separating equilibrium. Thus, there exists a minimum price $\hat{p}$ such that both types strictly prefer to pool optimally, rather than separate, when $\bar{p}>\hat{p}$. Q.E.D.

The preceding lemmas have laid the groundwork for the theorem concerning the form of the (pure-strategy) equilibria when both project types have a positive net present value and the level of uncertainty is high.

Theorem 1: When (5) is satisfied, there exists a unique separating equilibrium, with $H_{1}=q^{s}$ and $L_{1}=1$. However, if $\vec{p}>\hat{p}$, there is a pooling equilibrium that both types strictly prefer.

Proof: Lemma 3 has shown what quantities can be sold in a separating equilibrium. It remains to be shown that such an equilibrium actually exists. Let beliefs be $\pi\left(q_{1}\right)=\pi\left(q_{1}, q_{2}\right)=(1,0)$ if $q_{1} \leq q^{s}$ and $\pi\left(q_{1}\right)=\pi\left(q_{1}, q_{2}\right)=(0,1)$ if $q_{1}>$ $q^{s}$. By Lemma 1, some investor will offer a price equal to the investors' estimate of expected value. It is then optimal for the type $H$ to separate by selling $q^{s}$ at $t$ $=1$ and $1-q^{s}$ at $t=2$. Likewise, it is optimal for the type $L$ to sell $L_{1}=1$. Thus, a unique separating equilibrium exists.

Lemma 4 indicates that, if $\dot{p}>\hat{p}$, both types strictly prefer to sell $L_{1}=H_{1}=$ $q^{P}$ for the price $\bar{p}$. We also know from Lemma 2 that the optimal separating equilibrium at $t=2$ has $L_{2}=1-q^{P}$ and $H_{2}=Q\left(q^{P}\right)$.

Let beliefs be $\pi\left(q_{1}\right)=\pi\left(q_{1}, q_{2}\right)=(0,1)$ if $q_{1}>q^{P}$, and let $\pi\left(q_{1}\right)=\left(\omega_{H}, \omega_{L}\right)$ if $q_{1}$ 
$\leq q^{P}$. Also, let $\pi\left(q_{1}, q_{2}\right)=(1,0)$ if $q_{1} \leq q^{P}$ and $q_{2} \leq Q\left(q^{P}\right)$; otherwise, $\pi\left(q_{1}, q_{2}\right)=$ $(0,1)$. Given these beliefs and the prices implied by Lemma 1 , it is optimal for the two types to pool and sell $q^{P}$ at $t=1$ and then to separate at $t=2$. Thus, there is a pooling equilibrium that both types strictly prefer when $\bar{p}>\hat{p}$. Q.E.D.

So far it has been shown that, when there is a large amount of uncertainty, a separating equilibrium does exist. However, if the expected project value is sufficiently high, there is a pooling equilibrium that is strictly preferred by both types. This next theorem shows that, for all values of $\bar{p}$, there is also a mixedstrategy pooling equilibrium that Pareto-dominates the separating equilibrium. The type $L$ is indifferent between pooling and separating at $t=1$ in this case, and therefore randomizes between these options. However, the type $H$ strictly prefers to pool at $t=1$.

THEOREM 2: When (5) is satisfied, there exists a mixed-strategy pooling equilibrium that Pareto-dominates the separating equilibrium.

Proof: Define $\bar{p}(\alpha)$ to be the pooling price when the type $L$ pools with probability $\alpha$ :

$$
\bar{p}(\alpha) \equiv\left(\omega_{H} s_{H}+\alpha \omega_{L} s_{L}\right) /\left(\omega_{H}+\alpha \omega_{L}\right) .
$$

The same argument used in Lemma 1 indicates that this is the best price that would be offered if the type $L$ were to pool with probability $\alpha$. Note that $\bar{p} \leq \bar{p}(\alpha)$ $\leq s_{H}$, and higher values of $\alpha$ correspond to lower values of $\bar{p}(\alpha)$.

Consider trades at $t=1$ such that the type $L$ is indifferent to pooling at $t=1$ and then separating at $t=2$ :

$$
E U\left(\bar{p}(\alpha) \bar{q}(\alpha)+\left(s_{L}+\tilde{z}_{1}\right)(1-\bar{q}(\alpha))\right)=U\left(s_{L}\right) .
$$

Now suppose that the type $H$ were to sell a quantity $\tilde{q}(\alpha)$ for the price $\bar{p}(\alpha)$ at $t$ $=1$. The type $H$ would not be mimicked in the following period if he or she sold a quantity $q_{2}$ such that

$$
\begin{aligned}
& U\left(\bar{p}(\alpha) \bar{q}(\alpha)+\left(s_{L}+z_{1}\right)(1-\bar{q}(\alpha))\right) \\
& \quad \leq E U\left(\bar{p}(\alpha) \bar{q}(\alpha)+\left(s_{H}+z_{1}\right) q_{2}+\left(s_{L}+z_{1}+\tilde{z}_{2}\right)\left(1-\bar{q}(\alpha)-q_{2}\right)\right) .
\end{aligned}
$$

Define $H(q) \equiv E U\left(\bar{p}(\alpha) \bar{q}(\alpha)+\left(s_{H}+z_{1}\right) q+\left(s_{L}+z_{1}+\tilde{z}_{2}\right)(1-\bar{q}(\alpha)-q)\right) . H(\cdot)$ is a continuous and strictly increasing function for $0<q<1-\bar{q}(\alpha)$. Moreover, $H(0)$ is strictly less than the left-hand side of $(12)$, whereas $H(1-\bar{q}(\alpha))$ is strictly greater. Thus, there is a unique value of $q_{2}$ that solves (12) with equality. We write $\bar{Q}(\cdot)$ as the function that solves (12) for every value of $\alpha$.

For any value of $\alpha$, the ex ante expected utility of the high type is given by

$$
E U\left(\bar{p}(\alpha) \bar{q}(\alpha)+\left(s_{H}+\tilde{z}_{1}\right) \bar{Q}(\alpha)+\left(s_{H}+\tilde{z}_{1}+\tilde{z}_{2}\right)(1-\bar{q}(\alpha)-\bar{Q}(\alpha))\right) .
$$

There is an optimal value of $\alpha$, say $\alpha^{*}$, that maximizes (13). For every $\alpha \in(0,1)$, (13) is greater than the right-hand side of (12), and thus it exceeds $U\left(s_{L}\right)$. The type $H$ will therefore be strictly better off in the mixed-strategy pooling equilibrium with $\alpha=\alpha^{*}$ than in the separating equilibrium. Q.E.D.

The analysis for the case when the demand-side uncertainty is small follows the analysis just presented and will not be reproduced. The important difference 
in outcomes is that, when (5) does not hold, there will never be a separating equilibrium. This can be shown quite easily. If there were separation at $t=1$, the type $H$ would sell all equity by the second period. This would result in expected utility:

$$
E U\left(s_{H}+\left(1-H_{1}\right) \tilde{z}_{1}\right)>U\left(s_{L}\right) .
$$

The type $L$ would then have a positive incentive to mimic the type $H$ at $t=1$ rather than separate. Thus, only pooling equilibria exist when the cost of waiting is small.

The analysis to this point has dealt with a situation in which both types of projects have a positive net present value. If the low-value project has a negative net present value, it will still be undertaken with positive probability. If not, the type $H$ could set $H_{1}=1$ and receive $s_{H}$. However, it would then be worthwhile to undertake the type $L$ project after all. Thus, there can only be a mixed-strategy pooling equilibrium here. In equilibrium, the windfall that the type $L$ entrepreneur receives from pooling in the first period is just large enough to balance the fact that the project itself is a losing proposition.

\section{Summary}

This paper has developed a model in which equity could be sold twice, and it was equally costly for the two types to wait to sell. The pooling equilibria dominated the sequential equilibrium when the latter existed. More generally, the value of an insider's commitment not to sell is dependent on both the absolute and relative costs of waiting.

An important question is whether an entrepreneur would want to make a commitment not to sell beyond that imposed by Rule 144 of the Security Act of 1933. Such a commitment can be modeled by letting the type $H$ choose the distribution of $\tilde{z}_{1}$ and $\tilde{z}_{2}$. Since the separating equilibrium is dominated by the pooling equilibria, whatever the degree of uncertainty present, such a commitment is not an effective signal by itself.

The type $H$ can only differentiate himself or herself by using a signal that imposes different costs on the two types. Burning money would impose symmetric costs in the current model. Indeed, when signals that impose only slightly different costs are used, it can still be the case that only pooling equilibria exist.

Suppose that a cash flow accrues between periods, with a high-value project receiving a higher cash flow. For example, suppose that $\alpha \tilde{s}$ accrues to the firm after $t=1$ and that $(1-\alpha)\left(\tilde{s}+\tilde{z}_{1}+\tilde{z}_{2}\right)$ is returned at liquidation. There must be pooling whenever the type $L$ prefers $\alpha s_{L}+(1-\alpha)\left(s_{H}+\tilde{z}_{1}\right)$ to $s_{L}$. It follows that, for a given value of $\alpha$, only pooling equilibria exist when the level of uncertainty is small. At the same time, the type $H$ might prefer to commit not to sell for some length of time in this case since the cost of waiting is different for the two types now.

Even when there is some probability that the type $L$ will be detected between periods, pooling must still occur when the level of uncertainty is low. Suppose that there is a probability $\delta$ that the type $L$ entrepreneur will be detected between $t=1$ and $t=2$. There must be pooling if the type $L$ prefers a probability $\delta$ of 
receiving $\alpha s_{L}+(1-\alpha)\left(s_{L}+\tilde{z}_{1}\right)=s_{L}+(1-\alpha) \tilde{z}_{1}$, and a probability $1-\delta$ of getting $\alpha s_{L}+(1-\alpha)\left(s_{H}+\tilde{z}_{1}\right)$, to receiving $s_{L}$ for certain. Taking the values of $\alpha$ and $\delta$ as given, the type $L$ will prefer to imitate if the amount of uncertainty is sufficiently small. The problems raised here are pervasive to multiperiod signalling.

\section{REFERENCES}

Gale, Ian, 1987, Sequential trading in a competitive asset market with informed traders, Unpublished, University of Wisconsin.

Grinblatt, Mark and Chuan Yang Hwang, 1989, Signalling and the pricing of new issues, Journal of Finance 44, 393-420.

Grossman, Sanford and Motty Perry, 1986, Sequential bargaining under asymmetric information, Journal of Economic Theory 39, 120-154.

Kreps, David and Robert Wilson, 1982, Sequential equilibria, Econometrica 50, 863-894.

Kyle, Albert S., 1985, Continuous auctions and insider trading, Econometrica 53, 1315-1335.

Leland, Hayne E. and David Pyle, 1977, Informational asymmetries, financial structure and financial intermediation, Journal of Finance 32, 371-387.

Stiglitz, Joseph E., 1982, Information and capital markets, in William F. Sharpe, Cathryn M. Cootner, eds.: Financial Markets: Essays in Honor of Paul Cootner (Prentice-Hall, Inc., Englewood Cliffs, $\mathrm{NJ})$.

Welch, Ivo, 1989, Seasoned offerings, imitation costs, and the underpricing of initial public offerings, Journal of Finance 44, 421-449. 
Copyright of Journal of Finance is the property of Blackwell Publishing Limited and its content may not be copied or emailed to multiple sites or posted to a listserv without the copyright holder's express written permission. However, users may print, download, or email articles for individual use. 